\title{
Practice, Process, and Product: A self-reflexive inquiry of practice-led research in progress
}

\author{
EMILY HORNUM, Edith Cowan University.
}

\begin{abstract}
This paper investigates through a series of immersive and interactive installations how traditional notions of family archives have altered due to new media. Notions regarding the affect this might have on the performance of memory are central to this investigation. My creative praxis is situated within a practice-led research methodological paradigm. As this paper will discuss, practice-led research centralises interdisciplinary practices, fosters a holistic and experimental art-making process and is informed by theoretical frameworks and subjectivity. Photographs, videos and personal belongings are sourced from own family's archives. Consequently, my research approach positions me as artist, subject and researcher working within a framework that encourages subjectivity and reflexivity. This paper will explore the importance for transitional dialogues in practice-led research between theory and artistic practices, processes and products.
\end{abstract}

\section{KEYWORDS}

Practice-led research, installation art, family archives, memory, new media

\section{Introduction}

My Master of Arts by Research investigates the influence of new media on family archive materiality and the affect this might have on the performance of memory. With an undergraduate degree in Photography, I began my postgraduate study with the objective to create a large photographic installation reproducing my family archives using analogue techniques and experimental darkroom processes. This paper explores how my creative arts praxis manifested into a series of immersive and interactive installations incorporating photography, video, new media, objects, audiotapes and sound. In the first section to this paper I will briefly unpack the practice-led research paradigm to substantiate my position as researcher, creative arts practitioner and subject in this creative arts praxis. Discussed in this paper are six installation works from my current Master of Arts by Research to demonstrate how practice-led research can implement transitional dialogues between theory and artistic practices, processes and products. At the time of writing this paper four key elements identified that have significantly altered my conceptual framework and artistic practices are-Collating Data, Uncovering VHS Home Movies, Return to Analogue, and New Media Adventures. Firstly, when collating and digitising my family archives I was presented with myriad of technologies to transfer, view and edit these analogue 
media. This materialistic dialogue with my family archives reinforced the mediation of my bodily engagement and visual experience with archives across varying platforms. As a direct result, my creative arts praxis was pushed to extend beyond traditional analogue photographic process. Secondly, uncovering my family's VHS home movie tapes centralised video as an essential component in my research as illustrated in A Year in the Life of the Hornums (2014) and It's 10'oclock in the morning everybody and daddy's just gotten up to have breakfast (2015). Thirdly, studio practice and exhibiting in Becomings (2014) and The Substance of Memory (2015) directed the inclusion of $35 \mathrm{~mm}$ slides as a primary medium to my work. Lastly, this paper explores the influence of new media in my work using Online Archives of Family Objects (2015) and Audio Postcards (2015). Identifying these four critical stages illuminates that practice-led research fosters an experimental art making process, whilst, allowing for the incorporation of the self and the arts practitioner within the research process.

\section{Framing Praxis: the practice-led research paradigm}

My father died when I was 10 years old. After this rupture in my family life, family archives acquired an emotional and valuable significance. The photographs in our family albums intrigued me as objects and how they act as mnemonic devices. Susan Sontag describes photographs as 'an invitation to sentimentality...(that)...turn the past into an object of tender regard" $(2008,71)$. It can be said, that photographs offer a moment frozen in time - a tangible memory from the past that can be revisited as frequently as desired. Looking at my own life, photographs have undoubtedly reinforced my own memory of my father, my family narrative and my identity. Families generally provide our first interactions with the world as expounded by Jens Brockmeier.

As we get older we grow into the social communities that manifest our world, we are reappropriating these frames and memory practices spontaneously, without conscious effort or formal instruction, as we learn to communicate and to organise our individual memories in the process of everyday routines' (Brockmeier 2002, 23).

Memory is fundamental to our understanding of the world, our personal identity, family narrative and daily existence - it is essential to our ontology and epistemology (Gibbons 2007, Hutton 1987, Garde-Hansen 2011, Brockmeier 2002). Coupled with the death of my father, the role of memory has become evident in recent years with the witnessing of my Grandmother suffer from Alzheimer's disease-her memory has faded, deteriorated, fragmented and distorted. These subjective experiences have directed my interests as an arts practitioner. They are not intended to be explicit in my work, rather, to provide a richer context and deeper understanding to the reasons why I make art and the importance of the subjective experiences of the researcher within arts-based research. Practice-led research, as described by Robyn Stewart is a 'mix of artistic, cultural, scholarly and industrial concerns where the studio becomes an experimental arena for creative interactions, a space for critical analysis and renewal that enables a deeper understanding of artist's work processes' $(2006,1)$. 
Transparency in studio practice equips artists with the tools to work through their artists' practice whilst guided by theoretical discourses and embracing their existing subjective experiences and knowledge of the world.

Christopher Crouch contends that this holistic approach to research generates a space to reveal the 'dynamic relationship between the context, construction and articulation of the act' $(2007,108)$. In this approach, creative arts practitioners and researchers are provided with a framework to critically analyse their work from 'inside and outside their practice' (Stewart 2006, 2). This approach is vital in my creative arts praxis using my own family's archives of photographs, slides, VHS tapes, audiotapes and personal items collected from 1900s to 2013. I am intrinsically involved as arts practitioner, researcher and subject in my creative arts praxis. However, Elliot Eisner proposes that when involved $a s$ the researcher and within the research it is impossible to achieve complete objectivity.

Since what we know about the world is always a result of inquiry, it is mediated by mind. Since it is mediated by mind, the world cannot be known in its ontologically objective state. An objective world is postulated both as a general and as a particular entity. Since what we know about the world is a product of the transaction of our subjective life and a postulated objective world, these worlds cannot be separated (Eisner as cited in Sullivan 2005, 43).

To resolve this dilemma, Kim Etherington suggests that reflexivity 'opens up a space between subjectivity and objectivity to allow for an exploration and representation of the more blurred genres of our experiences...[whilst]...adding validity and rigor in research by providing information about the contexts in which data are located' (2004, 37). The inclusion of myself in the work is, therefore, supported as an intentional and supplementary element, whilst establishing boundaries to avoid 'solipsism, self-indulgence, navel gazing or narcissism' (Etherington 2004, 31). As further described by Crouch, 'reflexivity as a research method that takes into account the various ways in which the researcher influences research findings and thus what comes to be accepted as knowledge' $(2007,109)$. My creative arts praxis employs a practice-led research methodology incorporating reflexivity as a research method. This hybrid and dynamic research approach enables the complex layers of creative practice, subjective experiences and theoretical discourses to intersect and enrich the outcomes of arts based research.

\section{Collating Data}

The digitising of my family's analogue archives required varying devices and software in order to edit some of the obsolete and out-dated media. Marshall McLuhan proposes, 'the content of any medium is always another medium' (as cited in Dewdney \& Ride 2006, 21). McLuhan's ideas are evident through the process of archiving and duplicating my family archives-family photographic negatives became digitised, VHS tapes transferred to DVD's, 35mm slides scanned onto CD's and photographs scanned via a flatbed scanner. Norman Klein proclaims 'slides and 
magazines are not dying, simply embedding into other media-they changed "platforms" (2010, 87). The photograph shown in Figure 1 is from my family archives - it is a tangible artefact that has been imprinted with handwritten inscriptions. However, when this photograph is transferred onto the computer, it loses its context from the handwritten inscription and requires its own unique set of viewing conditions, devices, editing and printing technologies.

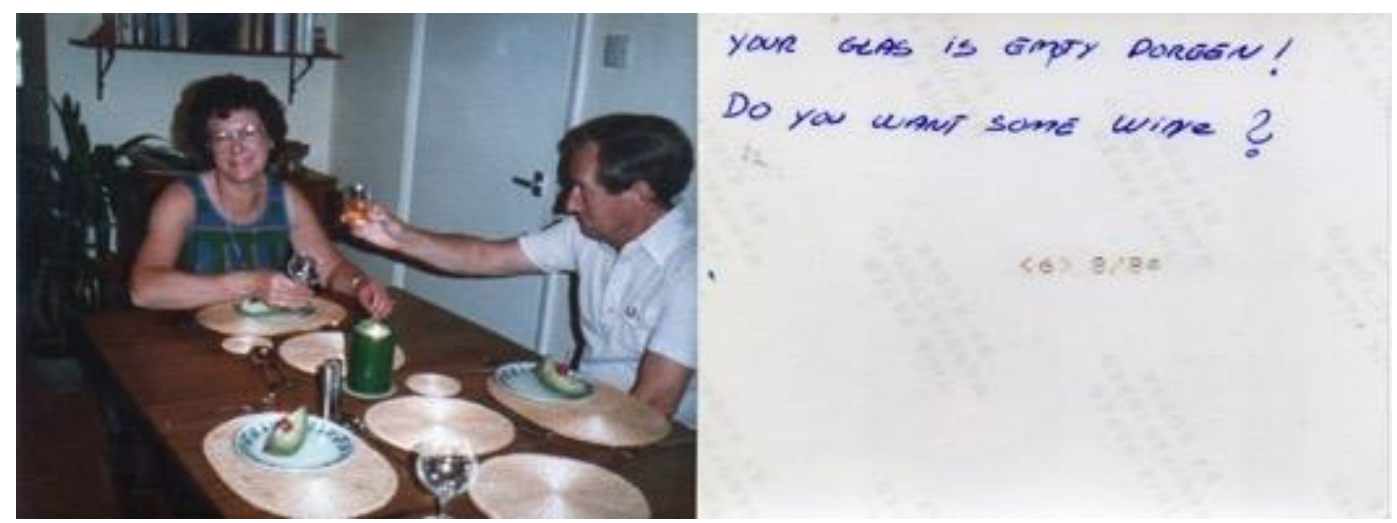

Figure 1. Your glas is empty Doreen! 2013, Emily Hornum. Image Copyright: Emily Hornum

Estelle Barrett emphasises that practice-led research nurtures this materialistic dialogue $(2009,143)$. The emotional, subjective and personal concerns that motivate creative arts research, 'operates not only on the basis of explicit and exact knowledge, but also that of tacit knowledge' (Barrett 2009, 143). The term experiential knowledge occurs as 'a continuum with normal processes of living, and is derived from an impulse to handle objects and to think and feel through their handling' (Barrett 2013, 64). As I 'handled' my family archives, I became aware of the bodily engagements and varying visual experiences we encounter across a range of media. The process of collating my archives explicitly highlighted the performative engagements across varying screens, devices and software to view, transfer and edit of our family archives recorded from myriad technologies.

\section{Uncovering VHS Home Movies}

Through the process of collating data, I discovered my family home movie VHS tapes - this unearthed media I had not considered using in my arts practice. The audio and moving footage of my childhood encoded onto the celluloid film evoked a nostalgic reference to the past. Once these analogue tapes were digitised, their materiality became evident - they had become vulnerable to environmental factors over time, whereby footage has gone missing or heavily scratched and distorted. Home movies function within families as an ethnographic record 'serving a ritualistic role in the way families construct themselves and their sense of a shared past' (Anderson 2011, 88). Yet, it is only recently that home movies have become recognised as important historical artefacts to reveal 'microhistories and alternative, nonmainstream, private and communal practices of memorialisation' (Rascaroli et al 
2014 , 1). Home videos were not intended to be viewed in public, but rather, as private records of family history shared between family members and close friends within domestic spaces. Patricia Zimmerman argues that home movies are subjective 'autoethnographies' that are 'generated from the point of view of participants' $(2008,20)$. This is reaffirmed in my family home movies tapes, predominantly recorded by my father. Although he is absent from the view of the camera, he is very much present in the director's role he plays from behind the lens. These tapes are a culmination of raw moments of our lives, scripted performances and family events such as Christmas or birthdays. They are fragmentary slices across a variety of spatial dimensions-footage is separated by days, months or years (Odin 2014). These fragments provide clues to a narrative that the viewer must piece together, which is not continuous like that presented in a traditional family photographic archive or album (Odin, 2014). This characteristic of home movies is exemplified in my creative arts praxis, whereby the chronology is further disrupted and fragments are spliced and edited almost at random from my home movie archive.

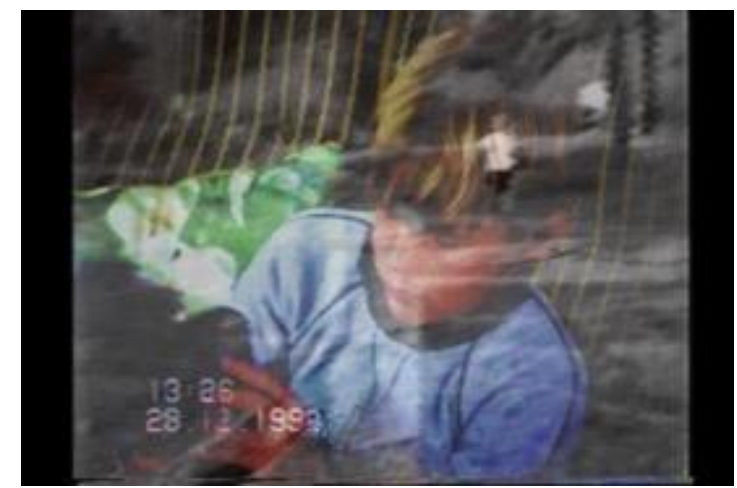

Figure 2. Experimental video work, 2014. Image copyright: Emily Hornum.

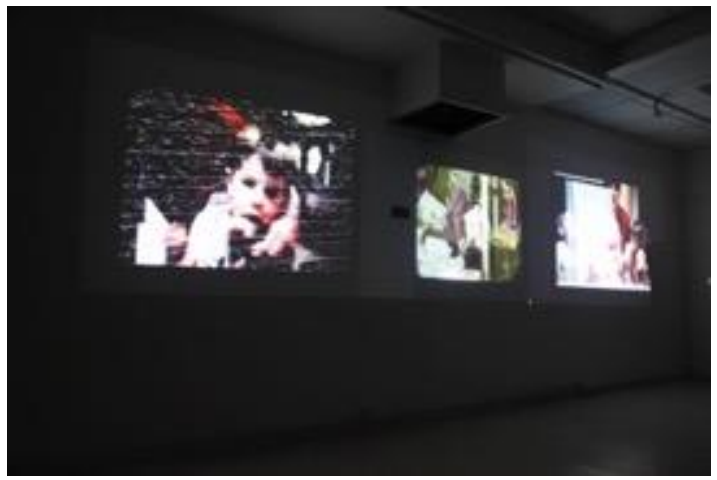

Figure 3. Studio experiments. 2014. Image copyright: Emily Hornum.

Once these VHS tapes were digitised, I was equipped with the technological capacity to splice fragments from these videos, manipulate the speed of the footage and reconfigure these videos into my own creative arts praxis. Initial studio experiments began with two intentions. Firstly, the aim was to overlay footage with other footage to represent the workings of memory to decipher between memories. The second aim was to overlay footage with recordings of the blank scratched celluloid film to highlight the materiality of the VHS analogue medium. After producing short videos from my family VHS tapes (screen shot seen in Figure 2), the next stage was to experiment with installation and audience engagement. When I experimented with multiple projections simultaneously, it became a confusion of imagery (Figure 3). Any narrative I was intending to convey became lost within this confusion. The decision to break away from the traditional constraints of the rectangular frame and use a circular format significantly redefined this installation. Rectangular screens dominate our everyday lives, whereas a circular frame has a clear reference to early photographic and optical inventions such as the camera obscura. Video 1 is a short clip extracted from A Year in the life of the Hornum (2014) - a 15-minute single-panel 
projection with circular fragments of recorded memories appearing on the screen in random sizes, duration and location (short excerpt seen in Video 1).

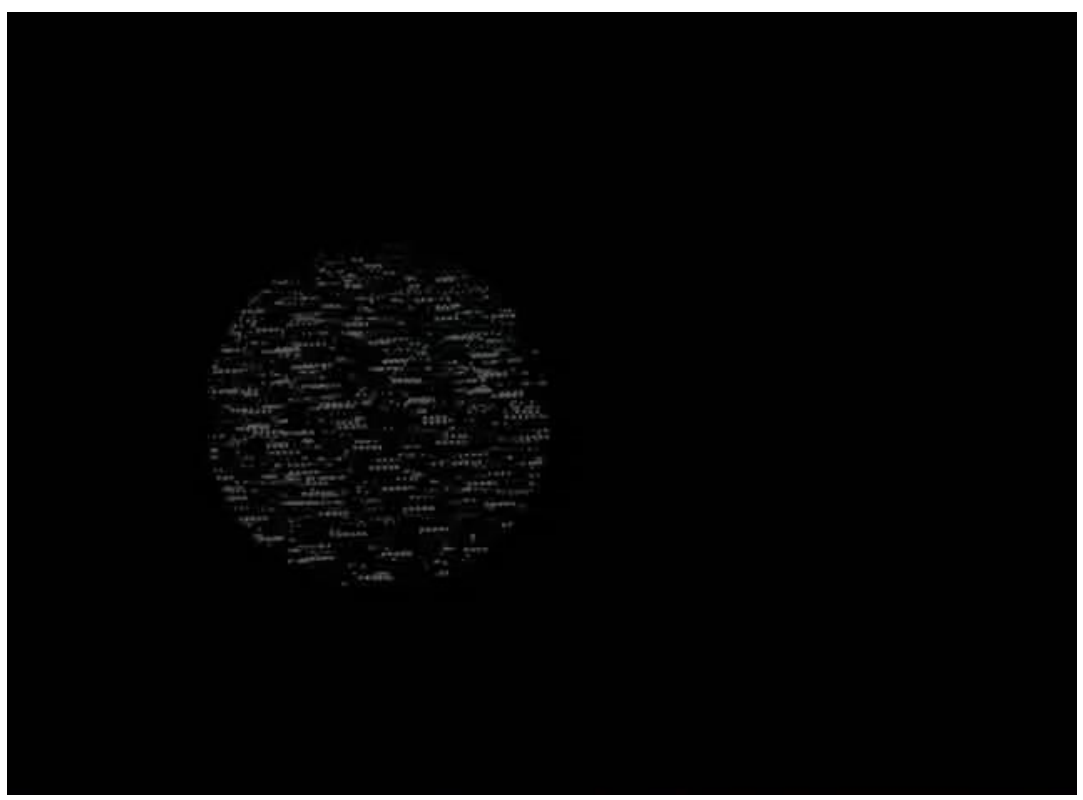

Video 1. A Year in the Life of the Hornums, 2014, Emily Hornum, 2014.

Each 'flash' of memory contains a splice of audio that has become unsynchronised due to the manipulation of the speed of the footage but not the audio. Overlaid across the whole video is an electronic instrumental song created by my brother, which I edited to gradually gain tempo as the video progresses. I exhibited A Year in the Life of The Hornums (2014) as part of Becomings (2014), a post-graduate exhibition and symposium at Spectrum Project Space in Perth (Figure 4). These dissemination strategies were significant opportunities to reflexively engage with audience interaction and to critically analyse my work in a gallery setting.

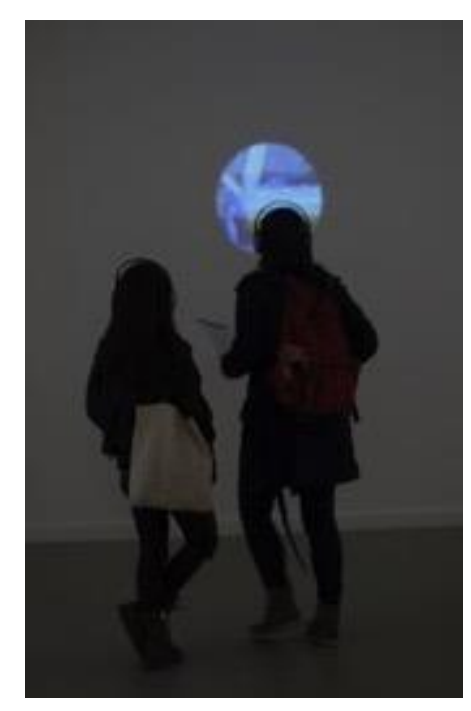

Figure 4. A Year in the Life of the Hornums, 2014, Emily Hornum. (installation view). Image copyright: Emily Hornum. 
The limitations of a group exhibition, however, restricted the scale of work, number of projectors, lighting and use of audible audio. The audience were required to use a set of headphones that evoked to some degree an intimacy to the work but also restricted the work to two audience members at a time. After Becomings (2014) exhibition I was intent on developing this installation to heighten the immersive qualities of installation art. This manifested in a multi-panel projection installation It's 10 'oclock in the morning everybody and daddy's just gotten up to have breakfast (2015) exhibited in The Substance of Memory (2015) at Spectrum Project Space, Perth. To create a dark projection room, this installation (Figure 5) was installed in a sectioned off a portion of the gallery with blackout fabric. Three projectors were used to simultaneously project three circular videos onto three different walls, resulting in scattered circular fragments of memories projected around the room. The audio was played through the internal speakers and the audience had no alternative but to become immersed in the darkened space, footage and sound. A short clip of this installation can be found here: https://www.youtube.com/watch?v=xWrrhyys8Ms.

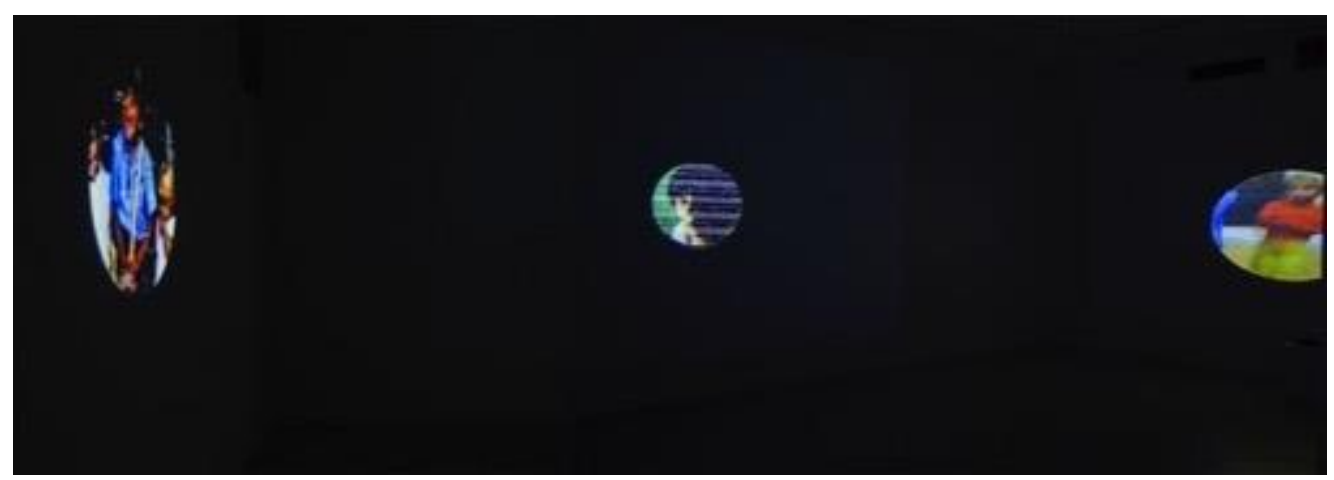

Figure 5. It's 10'oclock in the morning everybody and daddy's just gotten up to have breakfast, 2015, Emily Hornum. Multi-panel projection installation (installation view). Image copyright: Emily Hornum.

The material dialogue fostered through practice-led research has enabled the incorporation of a variety of media, such as VHS tapes and video. The opening up of studio practice has allowed myself to critically analyse my work-in-progress and develop a dialogue between the practice, process and product. This multi-panel projection installation has developed from the ability to situate myself inside and outside of my praxis (Etherington, 2004). Tangible evidence of studio processes and practices are intersected by theoretical discourses to underpin my research questions.

\section{Return to Analogue}

Central to this creative arts praxis is the investigation of how traditional notions of the archive have shifted due to new media. Therefore, incorporating traditional analogue processes was an important element to this creative praxis from the start. Analogue photography promoted the consumption and collection of tangible objects that allowed families to 'construct portrait chronicles' (Sontag 2008, 8). The materiality of analogue photographic images in their three-dimensional, tactile state as objects, 
existing in time and space and thus as cultural and social experience, become 'enmeshed with subjective, embodied and sensuous interactions' (Edwards \& Hart 2004, 1). In Becomings (2014) I exhibited A Year in the Life of the Hornums (2014) alongside an interactive photo-media installation Memory Viewing (2014). This was a selection of $35 \mathrm{~mm}$ slides that I had recreated from digitally editing and double exposing family negatives. These slides were presented with a slide viewer that the audience could use to view the slides (installation view seen in Figure 6). The placement of Memory Viewing (2014) next to A Year in the Life of the Hornums (2014) highlighted the physical and tactile nature of analogue mediums in contrast to the large tangible projection.

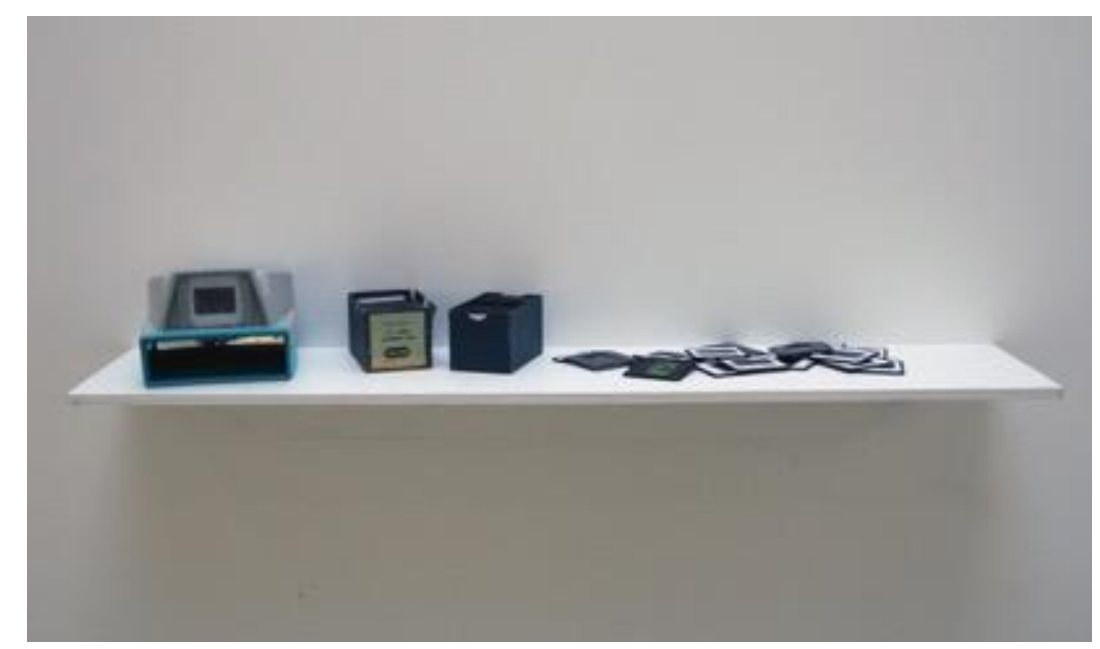

Figure 6. Memory Viewing (installation view), 2014. Emily Hornum. Image copyright: Emily Hornum

Tacita Dean's installation Film (2011) was a major influence on the development of Memory Work (2014). Dean shot the footage on $35 \mathrm{~mm}$ film using an 'anamorphic lens that doubles the width of the frame and then turned the image on its side, into a looming vertical' (Krauss 2012. 416). Film (2011) was painstakingly edited by Dean to pay homage to a 'form that is about to die, killed off by digital film making' (Higgins 2011, 1). The atmospheric nature of Dean's installation promotes nostalgia for a medium that is becoming obsolete, with her intentions not just to glorify the medium but also to advocate against its extinction. According to Dean, the evolution of film-making is likely to see the 'annihilation of one in order to achieve the complete and total accession of the other' $(2012,200)$. This notion can be applied to the photographic industry, in which the obliteration of analogue cameras, slides and film has almost succeeded due to the advances in digital cameras, hand-held devices and real time technologies. Despite the fact that the effects in Film (2011) are possible in digital post-production, they are 'resolutely, materially specific to film, manifesting both the conventions and constraints of celluloid and its shifting, ever-elastic capabilities' (Krauss 2012, 418). In addition, the vertical nature of Film (2011) embodies and immerses the viewer in a space that 'allows the viewer to not just watch 
a film but experience a film' (Knowles 2012, 5). Therefore, the inherent materiality of imagery devices alters our experience with family archives. To view slides in their complete viewing experience, it requires a darkened room, a projector and a screen. These material characteristics acquire the status of tangible and physical objects for remembrance. However, slides are also perceived as less tangible due to their mediation by technology in order to access these memories. Similar to Dean, I wanted to produce an immersive environment that allowed the audience to become embodied through the tactile nature of slides to transform the watching of slides into the experience of slides.

Slide Nights (2015) developed as a direct result of the opening up of studio inquiry and the critical investigation of artistic practices, processes and product. These sculptural formations are produced from over $300035 \mathrm{~mm}$ slides recreated from my family's archive and exhibited as part of The Substance of Memory (2015) (Figure 6). Robyn Stewart affirms 'the process of practice-led research are underpinned by constant emphasis on the ongoing and critical dialogues between studio and theory, process and product that are crucial for the practitioner researcher' $(2006,5)$. The Substance of Memory (2015) was not intended to demonstrate resolved works, but rather to use this opportunity to refine and develop my creative praxis through reflexivity. Similar to Dean's work, Slide Nights (2015) pays homage to a medium that is obsolete in mainstream family photography. Incorporated into the work are large sheets of acrylic mirrors to interplay with illusion, repetition and multiplicity. The audience becomes explicitly aware of their own bodily engagement within the work and the physicality of these structures is a constant reminder of the tangible and permanent status of analogue archives.

I experimented with the site-specific nature of these installations throughout my twoweek residency at Spectrum Project Space prior to The Substance of Memory (2015) opening. The installation of this work throughout this residency was documented via time-lapse (http://www.emilyhornum.com/\#!grid/c1wqk), which has been an extremely useful tool to reflect on the decisions made when immersed in studio practice. The final installation of Slide Nights (2015) integrated three projectionstwo digital works from VHS home movies and a live feed of the room. Two projections were pointed at the slide installation to interplay with light reflecting on and through the slides. In addition, a camera projected a live feed of the installation in the installation, a decision that occurred through responding to theoretical concerns and the site-specific nature of this installation. Firstly, this inclusion of the live feed heightened interactivity for the audience and successfully interwove the tangible and intangible nature of analogue and new media. The bodily engagement and participation from the audience is projected on the wall and in some locations, the audience appear multiple times. Secondly, the inclusion of the live feed projection was adapting to the large space of the gallery to produce an effective and immersive installation. 


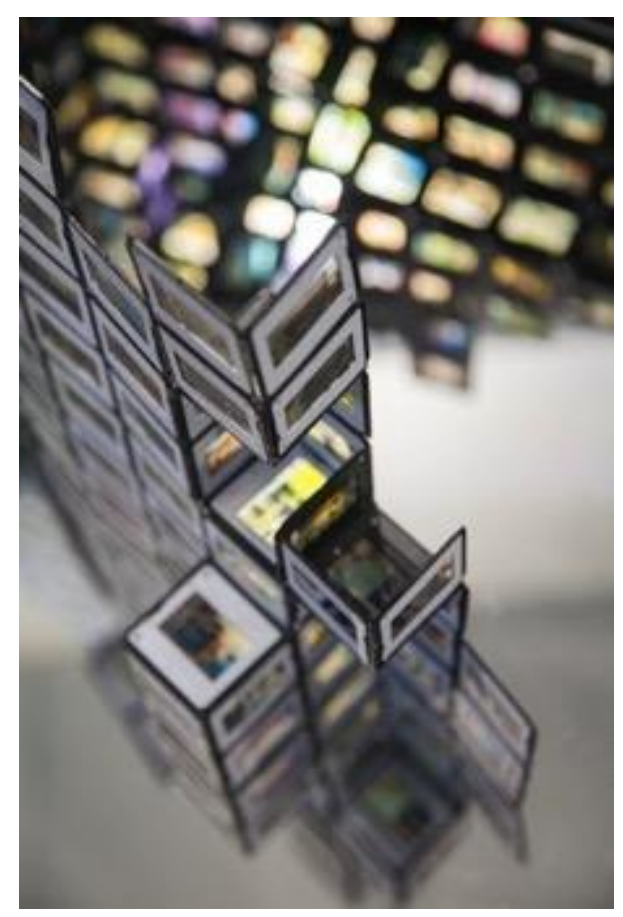

Figure 7. Slide Nights (installation view), 2015, Emily Hornum. 35mm slides (installation view). Image copyright: Emily Hornum

However, the most challenging component to this installation was the lighting. Due to the size of Spectrum Project Space and the existing lighting set-up, it was difficult to control the desired light throughout the exhibition space. The close up view of Slide Nights (2015), as seen in Figure 7, shows the ambient light over the work illuminated the slides from the outside, however the illumination from within each slide sculpture did not produce the desired result. Furthermore, working with reflective surfaces such as acrylic mirror and projections posed challenges in directing the light without being a distracting element to the viewer. As a result, Object Data Memory at Free Range Gallery in Perth will further explore these aspects in the final exhibition for this Master by Research in May 2015. Free Range Gallery is considerably smaller in size and will become a more intimate and immersive environment that challenges my creative arts praxis to develop further in relation to my theoretical perspectives and research questions explored in my exegesis. In addition, the aspects from the first installation, such as lighting, will be the main focus of studio practice in order to refine these components.

\section{New Media Adventures}

On the social media site Flickr, 'new photos are being uploaded at an estimated 15 images per second (equivalent to over 50,000 photographs added per hour by its millions of global users)' (Brøgger \& Newman 2010, 13). Western society has been transformed into an explicitly visual world with the surge in digital cameras and the emergence of social media sites such as Flickr, Facebook, YouTube, Pintrest etc. The increased interaction between humans and computers has generated the capacity for 
us to control our own images at an ever-increasing speed and mobility. Research suggests that images displayed, captured or created through digital media are viewed generally as more disposable, temporal and malleable (Van Dijck 2008, Hand 2012). Jose Van Dijck argues the materiality of digital photography can be seen to 'favor the functions of communication and identity formation at the expense of photography's use as a tool for remembering'" $(2008,3)$. The integration of these activities into everyday life has shifted the social use of photography from 'family to individual use, from memory tools to communication devices and from sharing (memory) objects to sharing experiences' (Van Dijck 2008, 4). This leads me to question the role of the family archive as technology develops at an ever-increasing rate and how future generations will remember their family history.

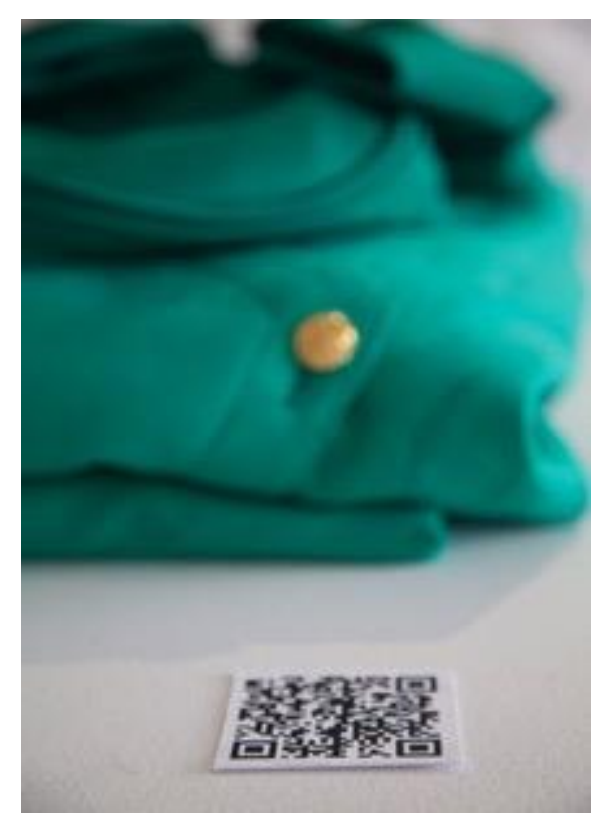

Figure 8. Online Archives of Family Objects, 2015, Emily Hornum. Family objects, photography, and new media (installation view). Image copyright: Emily Hornum

Online Archives of Family Objects (2015) stemmed from the material dialogue with the artefacts found within my family archives (Figure 8) and exhibited as part of The Substance of Memory (2015) in a museum style format. Six sentimental personal items were carefully folded and arranged alongside an item description, accession number and QR code directing the audience to a detailed online gallery of these artefacts. The mobile phone is an example how new media has become a sensory prosthetic, not just of vision, but of experience between the person and the machine (Shanks 2012, 2). The hybrid functions of a mobile phone, such as entertainment, organisation, navigation, communication and creation, assert themselves as metamorphic devices part of a networked society (Shanks, 2012). According to Alysih Wood, due to the fact we are not hardwired to read binary code, we rely on machines and technology to transcribe and mediate our experiences with digital images and information (2007). A smartphone with a QR barcode scanner app is required to view the complete work of Online Archives of Family Objects (2015). 
This technological interaction with the audience directly resonates with the theoretical perspectives underpinning my research proposing that new media mediates our participatory engagement with family archives.

Martin Hand argues that digital images do not 'necessarily reside in a family album, in a definitive hierarchy or order, and in the case of digitised analogue photos may not contain the discernible traces of their prior material context' $(2012,69)$. A photograph taken from a mobile phone does not carry the same connotations as a black and white vintage print that is aged, creased and inscribed on the back. Similarly, when viewing these digital photographs of these sentimental items displayed on various devices and screens they do not carry the same weight as the physical object in front of the viewer. The materiality and ontological status of analogue photography suggests that due to the chemical and physical processes that occur on material and tangible surfaces, they have a direct relationship to the object represented and in a sense are 'transcriptions of material properties' (Hand 2012, 62). The binary code of digital technologies is intangible and exists within a virtual space 'detached from the material object, and can be stored, accessed, altered, distributed and received in digital form through a range of devices and systems' (Hand 2012, 62). Consequently, the material nature of a photograph alters and transposes into an intangible electronic code that influences the reading, the experience, the interaction and the relationship with visual imagery. As part of my final exhibition Object Data Memory, I have integrated two installations from The Substance of Memory (2015)_Online Archives of Family Objects (2015) and I Forget Now (2015) to create a new work The Audio Postcard (2015). I Forget Now (2015), is an audio installation that connected photographs from my family archive with fragments of an audio interview between my mother and grandmother. This audio interview was recorded to capture some of my grandmother's memory before it disappeared a result of suffering from Alzheimer's. The Audio Postcard (2015), redirects audiences to a short audio fragment that accompanies the image on the postcard (Figure 9). This interactive and participatory engagement reinforces our performative relationship with technologies to record, store, narrate and share our family archives.
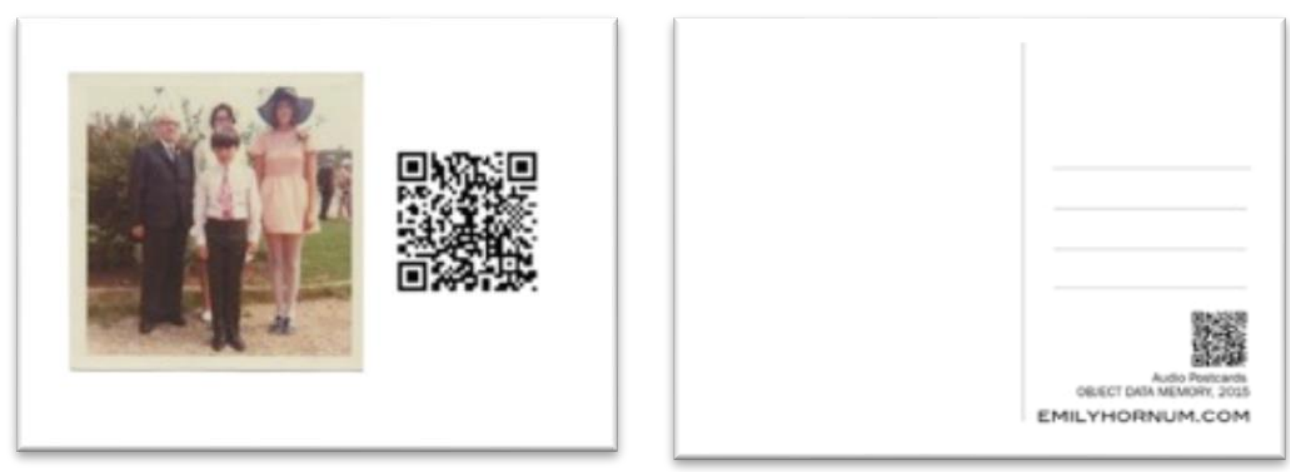

Figure 9. The Audio Postcard, 2015, Emily Hornum. Image copyright: Emily Hornum 


\section{Conclusion}

My Master by Research investigates the influence of new media on family archive materiality and the effect this might have on the performance of memory. I have used examples from my own creative arts praxis to illustrate the necessary and crucial dialogues between artistic practices, processes and product to generate a dynamic and holistic approach to arts-based research. This paper has identified four elements that significantly altered this project in terms of its conceptual framework and/or artistic practices. Firstly, the collating of data explicitly highlighted my material engagement with family archive materiality. Secondly, uncovering VHS home movie tapes introduced video as a valuable element. Thirdly, incorporating $35 \mathrm{~mm}$ slides into my installations emphasised analogue materiality of tangibility and physicality. And finally, the assimilation of new media resulted in response from theoretical guidance to support my research questions.

I am involved in this creative arts praxis as subject, researcher and arts practitioner. Therefore, this paper positions that the subjective experience of researcher should not be denied within the research process. On the contrary, a framework within which to reflexively engage with this subjective position should be fostered and nurtured to produce interdisciplinary and innovative outcomes. Through the investigation of my own creative arts praxis, I have positioned studio practice as an integral component in order to enable the merging of interdisciplinary practices to deliver greater support and inform the research questions underlining this creative arts praxis. The relationships between practice, process and product are never static or fixed-it is a cycle that transitions, repeats, and is never complete. At the same time, each 'stage' is weighted as vital and just as significant as the other in the context of the creative arts praxis.

\section{References}

Aasman, S. (2014) 'Saving Private Reels: Archival Practices and Digital Memories (formerly known as home movies) in the digital age', in L. Rascaroli, G. Young and B. Monahan (eds.) Amateur Filmamking: The Home Movie, The Archive, The Web, London, UK: Bloomsbury Publishing, pp. $245-$ 256

Anderson, S. (2011) Technologies of History: Visual Media and the Eccentricity of the Past, Lenanon: University of New England Press

Barrett, E., Bolt, Barbara. (2009) Practice as Research: approaches to creative arts Enquiry, London: I. B. Tauris

Barrett, E., Bolt, Barbara. (2013) Carnal Knowleldge: towards a new 'materialism' through the arts, London I. B. Tauris

Brockmeier, J. (2002). 'Remembering and Forgetting: Narrative as Cultural Memory', Culture \& Psychology, 8, 1, 15-43 
Brockmeier, J. (2010) 'After the Archive: Remapping Memory', Culture \& Psychology, 16, 1, 5-35

Brøgger, A., Newman., K. (2010) 'Persistence of vision: the interplay of vision, memory and media in contemporary art and science', in A. Brøgger and K. Newman (eds), Vision, Memory and Media, Liverpool: Liverpool University Press, pp. $13-25$

Crouch, C. (2007). 'Praxis and the Reflexive Creative Practitioner', Journal of Visual Art Practice, 6, 1, $105-114$

Dewdney, A., Ride, P. (2006) The New Media Handbook, Abington OX: Routledge

Edwards, E., \& Hart, J. (Eds.). (2004) Photographs Objects History: on the materiality of images, New York USA: Routledge

Etherington, K. (2004) Becoming a Reflexive Researcher: using ourselves in Research, London: Jessica Kingsley Publishers

Garde-Hansen, J. (2011) Media and Memory, Scotland: Edinburgh University Press

Gibbons, J. (2009) Contemporary Art and Memory: Images of Recollection And Remembarance, New York: I. B. Tauris \& Co. Ltd

Hand, M. (2012) Ubiquitous Photography: digital media and society series, Cambridge, Polity Press

Higgins, C. (2011) Tacita Dean's Turbine Hall Film Pays Homage to a Dying Medium. Available at http://www.theguardian.com/artanddesign/2011/oct/10/tacita-dean-filmturbine-hall. Accessed 27 April 2015

Hutton, P. (1987) 'The Art of Memory Reconceived: From Rhetoric to Psychoanalysis', Journal of the History of Ideas, 48, 3, 371 - 392

Hutton, P. (1994) 'Sigmund Frued and Maurice Halbwachs: The Problem of Memory in Historical Psychology', The History Teacher, 27, 2, 145 - 158

Klein, M., N. (2010) 'Cross-Embedded Media: a brief introduction', in A. Brøgger and K. Newman (eds), Vision, Memory and Media, Liverpool: Liverpool University Press, pp. $83-90$

Knowles, K. (2012) Tacita Dean Film, Millennium Film Journal. Available at http://www.readperiodicals.com/201210/2848429421.html. Accessed 27 April 2015-04-27.

Krauss, R. E. (2012) 'Frame by Frame', Artforum International, 51 ,12, 416419 
Odin, R. (2014) 'The Home Movies and Space of Communication', in L. Rascaroli, G. Young and B. Monahan (eds.), Amateur Filmmaking: The Home Movie, The Archive, The Web, London UK: Bloomsbury Publishing, pp. 15 26

Rascaroli, L., Young, Gwenda., Monahan, Barry. (2014) 'Amateur Filmamking: New Developments and Directions', in L. Rascaroli, G. Young and B. Monahan (eds.) Amateur Filmamking: The Home Movie, The Archive, The Web, London, UK: Bloomsbury Publishing, pp. 1 -12

Sontag, S. (2008). On Photography, Harmondsworth: Penguin.

Shanks, M. (2012) 'Digital Snaps: The New Face of Photography', in J. Larsen \& M. Sandbye (eds.), Mobile Media Photography: New Modes of Engagement. Available at http://documents.standord.edu/MichaelShanks/454?view=print. Accessed 27 April 2015.

Stewart, R. (2006) 'Mindful Practice: research and interdisciplinary dialogues in the creative industries, InSEA World Congress: Interdisciplinary Dialogues in Arts Education, Viseu, Portugal, 1 - 5 March 2006

Sullivan, G. (2005) Arts Practice As Research: Inquiry in the visual arts, California: Sage Publications Inc.

Van Dijck, J. (2008) ‘Digital photography: Communication, Identity, Memory’, Visual Communication, 7,1, 57-76

Woods, A. (2007) Digital Encounters, Abington OX: Routledge

Zimmermann, P. (2008) 'The Home Movie Movement: Excavations, Artifacts, Minings', in P. Zimmermann \& K. Ishiuka (eds.), Mining the Home Movies: Excavations in Histories and Memories, USA: University of Calfornia Press, pp. $1-26$

Emily Hornum is an emerging artist with an interdisciplinary practice working across photography, mixed media, new media and installation. Graduating with a Bachelor of Photography with Queensland College of Art, Griffith University, Australia in 2009 and was awarded an Academic Award for Excellence. Currently, she is undertaking a Masters of Visual Arts by Research at Edith Cowan University, Perth, Australia. Her research investigates through installation art how new media has altered family archive materiality and the affect this has on the performance of memory. Hornum has exhibited her work in numerous solo and group shows including Queensland Centre for Photography, FotoFreo 2012 and Fringe World Festival Perth 2015. In 2015 she has exhibited solo shows at Spectrum Project Space and Free Range Gallery and took part in The 3rd Space Project, a group exhibition with University of Shanghai Science and Technology. 